\title{
Active Glucagon-like Peptide-1 Measurement
}

National Cancer Institute

\section{Source}

National Cancer Institute. Active Glucagon-like Peptide-1 Measurement. NCI Thesaurus.

Code C80164

The determination of the amount of active glucagon-like peptide- 1 present in a sample. 